\title{
Improvement of Paclitaxel-Associated Adverse Reactions (ADRs) via the Use of Nano-Based Drug Delivery Systems: A Systematic Review and Network Meta-Analysis
}

This article was published in the following Dove Press journal:

International Journal of Nanomedicine

\section{Pi-Ling Chou ${ }^{1,2, *}$ \\ Ya-Ping Huang (iD $3,4, *$ \\ Meng-Hsuan Cheng (D) ${ }^{5-7}$ \\ Kun-Ming $\mathrm{Rau}^{8,9}$ \\ Yi-Ping Fang $2,3,10$ \\ 'School of Nursing, College of Nursing, Kaohsiung Medical University, Kaohsiung, Taiwan; ${ }^{2}$ Department of Medical Research, Kaohsiung Medical University Hospital, Kaohsiung, Taiwan; ${ }^{3}$ School of Pharmacy, College of Pharmacy, \\ Kaohsiung Medical University, Kaohsiung, Taiwan; ${ }^{4}$ Department of Pharmacy, Antai Tian-Sheng Memorial Hospital, Pingtung, Taiwan; ${ }^{5}$ Division of Pulmonary and Critical Care Medicine, Department of Internal Medicine, Kaohsiung Medical University Hospital, Kaohsiung, Taiwan; ${ }^{6}$ School of Medicine, College of Medicine, Kaohsiung Medical University, Kaohsiung, Taiwan; ${ }^{7}$ Department of Respiratory Therapy, College of Medicine, Kaohsiung Medical University, Kaohsiung, Taiwan; ${ }^{8}$ Department of Hematology-Oncology, E-Da Cancer Hospital, Kaohsiung, Taiwan; '9 School of Medicine, College of Medicine, I-Shou University, Kaohsiung, Taiwan; ${ }^{10}$ Regenerative Medical and Cell Therapy Center, Kaohsiung Medical University, Kaohsiung, Taiwan}

*These authors contributed equally to this work

Correspondence: Yi-Ping Fang 100, Shih-Chuan Ist Road, San Ming District, Kaohsiung, Taiwan 80708

Tel +886 73I2II0I ext. 226।

$\mathrm{Fax}+88673210683$

Email ypfang@kmu.edu.tw
Background: Paclitaxel is wildly used in chemotherapy, however, the adverse drug reactions (ADRs) occurred frequently. Various novel nano-based paclitaxel delivery systems were developed. The aim performed systemically review and meta-analyses to evaluate the effect adverse drug reactions (ADRs) of paclitaxel and its nano-based delivery systems.

Methods: Systematically searched PubMed, Embase, Web of Science, Cochrane, Clinicalkey, Clinicaltrial.com, ASCO and ESMO. Data of adverse effect were analyzed to odds ratio (ORs) with $95 \%$ confidence interval (CI). The quality of studies was assessed with CASP Randomised Controlled Trial Checklist. Statistical analysis was used WinBUGS software (version 1.4.3) with the NetMetaXL interface (version 1.6.1).

Results: Twenty-one studies, including 7011 patients and 6 paclitaxel formulations fulfilled the inclusion criteria. In all grade hypersensitivity reactions, comparing to SB-P, people with Lip-P had 0.19 times $(95 \% \mathrm{CI}=0.02,1.3)$ of chance, with Nab-P had 0.47 times $(95 \% \mathrm{CI}=$ $0.11,1.40)$ of chance, with PPX had 0.44 times $(95 \% \mathrm{CI}=0.03,5.7)$ of chance for all grade adverse effect. In All grad neutropenia, comparing to Lip-P, people with SB-P had 0.83 times $(95 \% \mathrm{CI}=0.15,4.81)$ of chance for all grade adverse effect; comparing to PM-P, people with SB-P had 0.73 times $(95 \% \mathrm{CI}=0.22,2.42)$ of chance for all grade adverse effect. In leucopenia, comparing to Nab-P, people with SB-P had 0.66 times $(95 \% \mathrm{CI}=0.50,0.87)$ of chance for all grade adverse effect; comparing to PM-P, people with SB-P had 0.64 times $(95 \% \mathrm{CI}=0.32,1.16)$ of chance for all grade adverse effect. The rate of incidence in peripheral sensory neuropathy, myalgias and arthralgias tend to no significant differences between different formulations.

Conclusion: Nano-based paclitaxel delivery resulted in fewer hypersensitivity reactions than solvent-based delivery. However, the incidence of neutropenia and leucopenia was higher in nano-based than solvent-based paclitaxel delivery. Dose-dependent ADRs were more frequent in paclitaxel anticancer treatment.

Keywords: paclitaxel, nano-based paclitaxel delivery systems, adverse reaction, network meta-analysis

\section{Background}

Paclitaxel (Taxol ${ }^{\circledR}$ injection) is a chemotherapeutic agent widely used for the effective treatment of various types of cancer. Paclitaxel was approved by the United States (US) Food and Drug Administration (FDA) for the treatment of ovarian carcinoma, breast carcinoma, advanced non-small cell lung carcinoma, 
and acquired immunodeficiency syndrome (AIDS)-related Kaposi's sarcoma in combination with or without other chemotherapeutic agents. Nowadays, paclitaxel has been used for two decades both as a single agent and in combination chemotherapy. However, it is generally not well tolerated as it may cause serious adverse drug reactions (ADRs), including hypersensitivity reactions, hematological toxicity, peripheral sensory neuropathy, and myalgia or arthralgia. ${ }^{1}$ To prevent serious ADRs, posology is important, particularly with regard to the administration of cytotoxic agents. Moreover, patients must be treated preventively with corticosteroids, antihistamines, and $\mathrm{H}_{2}$ antagonists prior to paclitaxel administration. However, the efficacy of preventive measured is limited. ${ }^{2}$

Although paclitaxel treatment is associated with several ADRs, it is still used by oncologists to manage various cancers because of its high efficacy. To reduce the incidence of paclitaxel-associated ADRs and to facilitate its accurate distribution to tumor cells, researchers and pharmaceutical companies have investigated and developed nano-based drug delivery systems for paclitaxel. New generations of drug delivery systems make use of nano-scale carrier systems, resulting in more specific targeting, reduced toxicity while maintaining therapeutic effects, as well as greater safety and biocompatibility.,

Paclitaxel $\left(\mathrm{C}_{47} \mathrm{H}_{51} \mathrm{NO}_{14}\right.$, molecular weight $\left.853.93 \mathrm{Da}\right)$ is a highly hydrophobic compound ( $\log \mathrm{P}=3.96$, aqueous solubility $<0.01 \mathrm{mg} / \mathrm{mL}$ ) as its chemical structure consists of a taxane ring link with a four-membered oxetane side ring and an active homochiral ester side chain. ${ }^{5}$ First-generation paclitaxel was formulated as a solution and administered via intravenous (IV) infusion containing polyoxyl 35 castor oil (Cremophor $\mathrm{EL}^{\circledR}$ ) and dehydrated ethanol (1:1 ratio, v/v), a powerful solubilizer combination increase water solubility. ${ }^{6}$ However, most patients exhibited hypersensitivity symptoms, bronchospasms, and hypotension as a result of polyoxyl 35 castor oil treatment. Previous studies ${ }^{7,8}$ revealed that polyoxyl 35 castor oil induced histamine release and hypotension, and hypersensitivity reactions consequently occurred during both IV infusion and bolus administration. Unfortunately, clinical prevention strategies were unable to completely resolve toxicity problems. In addition, the chemical and physical in-use stability of paclitaxel solutions prepared for infusion was another important issue. Commercially available paclitaxel solutions used immediately after dilution with $5 \%$ dextrose or $0.9 \%$ sodium chloride injection show greater safety outcome. The diluted formulation yields a final concentration of $0.3-1.2 \mathrm{mg} / \mathrm{mL}$ drug, which is considerably higher than the
$0.01 \mathrm{mg} / \mathrm{mL}$ aqueous solubility of paclitaxel, posing the risk of drug precipitation upon dilution. ${ }^{9}$

To increase solubility, several approaches were investigated, including the formation of salts and addition of charged complexing agents, although these were ineffective. ${ }^{10}$ Nano-based delivery systems are predominantly used to improve bioavailability and stability, alter pharmacokinetics, increase efficient drug targeting, and enhance therapeutic outcomes. ${ }^{11}$

There are five nano-based paclitaxel delivery systems approved by the FDA or in clinical trial progress, including nanoparticle albumin-bound paclitaxel (Nab-P), liposomal paclitaxel (Lip-P), polymeric micelle paclitaxel (PM-P), polymer-drug paclitaxel conjugates (PPX), and paclitaxel injection concentrate for nanodispersion (PICN).

Nab-P, an agent that combines paclitaxel with albumin, crosses endothelial cells via active transport into tumors by a specific pathway that is activated by albumin binding to glycoprotein 60 (gp60). ${ }^{12}$ Additionally, secreted protein acidic and rich in cysteine (SPARC), which is present in certain neoplasms, has been shown to bind albumin and thus facilitates intratumor accumulation of Nab-P. ${ }^{13}$ The maximum tolerated dose (MTD) of Nab-P was determined to be $300 \mathrm{mg} / \mathrm{m}^{2}$, which is $70 \%$ higher than that of $\mathrm{Sb}-\mathrm{P}\left(175 \mathrm{mg} / \mathrm{m}^{2}\right) .^{14}$

Lip-P is an agent that entraps paclitaxel within liposomal phospholipid bilayers to increase water solubility and decrease ADRs. Lip-P displayed nonlinear pharmacokinetics that may be related to sequestration by the reticuloendothelial system. Once paclitaxel is released from liposomes, it rapidly binds to serum proteins and subsequently follows the same pharmacokinetic processes as $\mathrm{Sb}-\mathrm{P}$. Changes in the tissue distribution of paclitaxel may be responsible for the increased MTD of Lip-P compared with that of Sb-P. In other words, a lower dose of paclitaxel could produce the same therapeutic effect. ${ }^{15}$

PM-P is a nanoscopic core structure formed with paclitaxel and amphiphilic block copolymer monomethoxypoly (ethylene glycol)-block-poly (D, L-lactide). ${ }^{16}$ The uptake of PM-P occurs via endocytosis. Captured PM-P structures in endocytic vesicles are transported to lysosomes and the drug is released. ${ }^{5}$ The antitumor activity of PM-P is greater than that of Sb-P and higher drugs concentrations are achieved in tumor tissues. ${ }^{17} \mathrm{~A}$ Phase I trial testing PM-P revealed an MTD of $390 \mathrm{mg} / \mathrm{m}^{2}{ }^{18}$

PPX, a polymer-drug conjugate, is an anionic polymeric macromolecule in which paclitaxel is conjugated to poly (L-glutamic acid) through its 2'-hydroxyl group by an ester bond linkage. ${ }^{19}$ Because of its large number of anionic 
charges, PPX is water-soluble. The ester bond is stable enough to resist spontaneous hydrolysis, and is not broken down by plasma esterases. ${ }^{20}$ Compared with Sb-P, PPX presents several advantages. Alopecia, nausea, vomiting, and hypersensitivity reactions are rarely observed and routine premedication is therefore not required.

PICN is a polymeric-lipidic, self-assembly nanoparticle formulation of paclitaxel that is stabilized by a polymer and a lipid. A phase I study showed that the MTD of PICN is $325 \mathrm{mg} / \mathrm{m}^{2}$ and that its administration did not cause hypersensitivity reactions. $^{21}$

Most studies investigating nanoparticle paclitaxel delivery were performed using head-to-head comparative studies to investigate effectiveness; however safety profiles were not considered. The aim of this study was to compare the ADRs of various paclitaxel formulas by collecting and analyzing randomized controlled trial (RCTs).

\section{Methods}

\section{Literature Search}

We carried out a systematic search of several electronic databases, including Pubmed, Embase, Web of Science, Cochrane, Clinicalkey, and Clinicaltrial.com, as well as the American Society of Clinical Oncology (ASCO) and European Society of Medical Oncology Conference (ESMO). Additionally, additional information was collected from the studies. The following keywords were used for searching: (solvent based OR cremophor OR paclitaxel) AND (albumin OR micelle OR liposome OR polymeric OR lipidic) AND (adverse effect OR toxicity) AND randomized controlled trial. There were no restrictions regarding language, year published, patient age, or gender.

\section{Eligibility Criteria}

The following criteria were used to select studies: (1) full paper or conference abstract available, (2) treatment used was a paclitaxel formulation, (3) studies that reported ADRs from paclitaxel-containing regimens, (4) studies designed as RCTs. Studies presenting duplicate data or no data regarding ADRs were excluded.

\section{Data Extraction}

Investigators independently extracted data according to a predefined form including the following information: first author, year of publication, study location, median/ mean age, number of subjects, treatment regimens, dosage, type and grade of ADRs, and premedication information.

\section{Quality Assessment}

The quality of included studies was evaluated using the Critical Appraisal Skills Programme (CASP) RCT checklist. ${ }^{22}$ This is a checklist with 11 questions designed to systematically review studies. However, this checklist was designed as an educational pedagogical tool, and not as a scoring system.

\section{Statistical Analysis}

This network meta-analysis (NMA) was performed using a Bayesian random effects model following the Markov Chain Monte Carlo method. ${ }^{23}$ Statistical analysis was carried out using the WinBUGS software (version 1.4.3) and the Microsoft-Excel-based tool NetMetaXL interface (version 1.6.1). The prior distribution of ADRs was unclear and the model involved calculations on 40,000 iterations with 20,000 iterations as burn-in. The model used the total number of events and number of patients to estimate odds ratios. Rankograms and surface under the cumulative ranking (SUCRA) were used to examine ranking probabilities. Inconsistencies in the analysis were identified via visual examination.

\section{Results}

The basic information of nano-based paclitaxel delivery systems reviewed here is summarized in Table 1. During the

Table I Paclitaxel in Various Nano-Based Drug Delivery Systems

\begin{tabular}{|l|l|l|l|l|l|}
\hline $\begin{array}{l}\text { Brand } \\
\text { Name }\end{array}$ & Abraxane $^{\circledR}$ & Lipusu $^{\circledR}$ & Genexol $^{\circledR}$ PM & $\begin{array}{l}\text { Xyotax }_{\text {TM }} \\
\text { (OPAXIO) }\end{array}$ & Taclantis $^{{ }^{\mathrm{TM}}}$ (Bevetex $^{\circledR}$ ) \\
\hline $\begin{array}{l}\text { Nano-based } \\
\text { carrier type }\end{array}$ & $\begin{array}{l}\text { Nanoparticle } \\
\text { albumin-bound } \\
\text { paclitaxel (Nab-P) }\end{array}$ & $\begin{array}{l}\text { Liposomal } \\
\text { paclitaxel (Lip-P) }\end{array}$ & Polymeric micelle paclitaxel (PM-P) & $\begin{array}{l}\text { Polymer-drug } \\
\text { conjugates of } \\
\text { paclitaxel (PPX) }\end{array}$ & $\begin{array}{l}\text { Paclitaxel injection concentrate for } \\
\text { nanodispersion (PICN), } \\
\text { Nanotecton technology }\end{array}$ \\
\hline $\begin{array}{l}\text { Particle size } \\
\text { Memo }\end{array}$ & $\begin{array}{l}130 \mathrm{~nm} \\
\text { Human serum } \\
\text { albumin } \\
\text { nanoparticle }\end{array}$ & $\begin{array}{l}400 \mathrm{~nm} \\
\text { EndoTAG } \\
\text { positive charge } \\
\text { liposome }\end{array}$ & $\begin{array}{l}25-50 \mathrm{~nm} \\
\text { Monomethoxy poly(ethylene glycol)- } \\
\text { block-poly(D,L-lactide) (mPEG- } \\
\text { PDLLA) copolymer }\end{array}$ & $\begin{array}{l}\text { N.A. } \\
\text { Poly-L-glutamate }\end{array}$ & $\begin{array}{l}\text { Polyvinylpyrrolidone (PVP)/ } \\
\text { paclitaxel self-assembly }\end{array}$ \\
\hline
\end{tabular}

Abbreviation: N.A., not applicable. 
literature search, 592 articles were selected. After screening of the titles and abstracts, 66 titles were identified. After observation of the eligibility criteria, 19 primary articles were selected, including 16 articles in English and three articles in Chinese (Figure 1). ${ }^{5,18,20,21,24-38}$ These articles comprised a total of 5787 participants and six paclitaxel formulations including solvent-based paclitaxel, Nab-P, Lip-P, PM-P, PPX, and PICN. The regimens and dose characteristics of the included studies are presented in Table 2 . The cancer types, age, gender and clinical statement are shown in Table 3 . The structure of paclitaxel in various nano-based drug delivery systems are shown in Figure 2. The ADRs discussed in this study include hypersensitivity reactions, neutropenia, leucopenia, peripheral sensory neuropathy, myalgia, and arthralgia. The quality of the included trials was moderate to high, and most of the trials were described as open-label or had no blinding description.

\section{Incidence of Hypersensitivity Reactions}

The incidence of hypersensitivity reactions of any grade, the number of interventions were five with nine studies involving

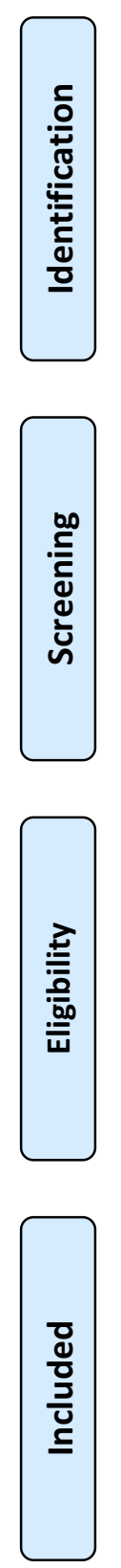

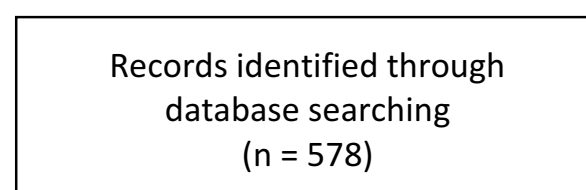

$=578)$

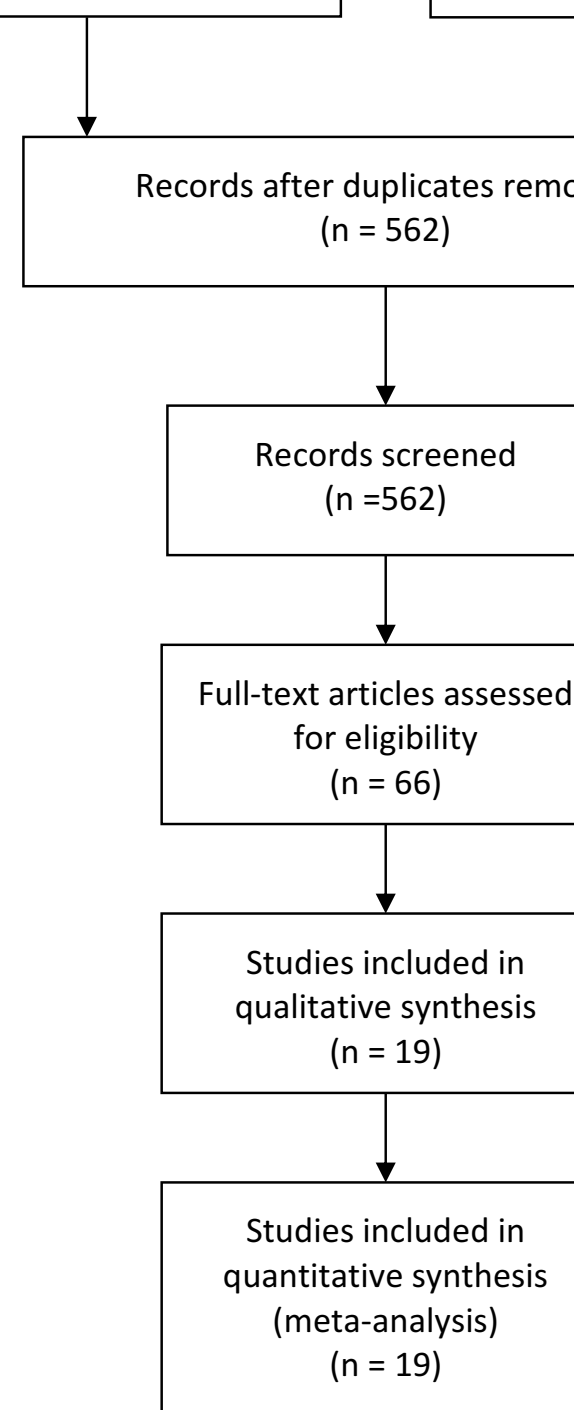

Figure I Stepwise procedures for database search and selection of eligible studies. 
Table 2 Characteristics of Regimens and Dose in All Studies Included in the Network Meta-Analysis

\begin{tabular}{|c|c|c|c|c|c|c|}
\hline Author (Year) & $\begin{array}{l}\text { Arm I Participants } \\
\text { (n) }\end{array}$ & Arm I Regimen & Arm I Dose & $\begin{array}{l}\text { Arm } 2 \\
\text { Participants (n) }\end{array}$ & Arm 2 Regimen & Arm 2 Dose \\
\hline Lee $(2018)^{18}$ & 48 & $S B-P+C b$ & $175 \mathrm{mg} / \mathrm{m}^{2}$, DI Q3W & 50 & $P M-P+C b$ & $260 \mathrm{mg} / \mathrm{m}^{2}$, DI Q3W \\
\hline Gianni $(2018)^{24}$ & 335 & $S B-P \rightarrow A(E)(F E) C$ & $90 \mathrm{mg} / \mathrm{m}^{2}, \mathrm{Dl} / 8 / \mathrm{l} 5 \mathrm{Q} 4 \mathrm{~W}$ & 337 & $\mathrm{~N}-\mathrm{P} \rightarrow \mathrm{A}(\mathrm{E})(\mathrm{FE}) \mathrm{C}$ & $125 \mathrm{mg} / \mathrm{m}^{2}, \mathrm{DI} / 8 / 15 \mathrm{Q} 4 \mathrm{~W}$ \\
\hline Park $(2017)^{25}$ & 107 & SB-P & $175 \mathrm{mg} / \mathrm{m}^{2}$, DI Q3W & 105 & PM-P & $260 \mathrm{mg} / \mathrm{m}^{2}$, DI Q3W \\
\hline \multirow[t]{2}{*}{ Shitara $(2017)^{26}$} & 243 & SB-P & $80 \mathrm{mg} / \mathrm{m}^{2}, \mathrm{Dl} / 8 / \mathrm{l} 5 \mathrm{Q} 4 \mathrm{~W}$ & 244 & N-P & $260 \mathrm{mg} / \mathrm{m}^{2}$, DI Q3W \\
\hline & & & & 241 & N-P & $100 \mathrm{mg} / \mathrm{m}^{2}, \mathrm{DI} / 8 / \mathrm{l} 5 \mathrm{Q} 4 \mathrm{~W}$ \\
\hline \multirow[t]{2}{*}{ Jain $(2016)^{21}$} & 58 & N-P & $260 \mathrm{mg} / \mathrm{m}^{2}$, DI Q3W & 64 & $\mathrm{PICN}$ & $260 \mathrm{mg} / \mathrm{m}^{2}$, DI Q3W \\
\hline & & & & 58 & $\mathrm{PICN}$ & $295 \mathrm{mg} / \mathrm{m}^{2}$, DI Q3W \\
\hline Untch $(2016)^{27}$ & 601 & $\begin{array}{l}\text { SB-P(H+Per }) \rightarrow E C \\
(H+P e r)\end{array}$ & $80 \mathrm{mg} / \mathrm{m}^{2}, \mathrm{DI} / 8 / \mathrm{l} 5 \mathrm{Q} 4 \mathrm{~W}$ & 605 & $\begin{array}{l}\mathrm{N}-\mathrm{P}(\mathrm{H}+\mathrm{Per}) \rightarrow \mathrm{EC} \\
(\mathrm{H}+\mathrm{Per})\end{array}$ & $150 \mathrm{mg} / \mathrm{m}^{2}, \mathrm{DI} / 8 / 15 \mathrm{Q} 4 \mathrm{~W}$ \\
\hline Rugo $(2015)^{28}$ & 272 & $S B-P+B e v$ & $90 \mathrm{mg} / \mathrm{m}^{2}, \mathrm{Dl} / 8 / \mathrm{l} 5 \mathrm{Q} 4 \mathrm{~W}$ & 263 & $\mathrm{~N}-\mathrm{P}+\mathrm{Bev}$ & $150 \mathrm{mg} / \mathrm{m}^{2}, \mathrm{DI} / 8 / 15 \mathrm{Q} 4 \mathrm{~W}$ \\
\hline Wang $(2014)^{29}$ & 27 & $S B-P+C b$ & $175 \mathrm{mg} / \mathrm{m}^{2}$, DI Q3W & 27 & Lip-P + Cb & $175 \mathrm{mg} / \mathrm{m}^{2}$, DI Q3W \\
\hline Awada $(2014)^{30}$ & 28 & SB-P & $90 \mathrm{mg} / \mathrm{m}^{2}, \mathrm{Dl} / 8 / \mathrm{l} 5 \mathrm{Q} 4 \mathrm{~W}$ & 57 & Lip-P & $88 \mathrm{mg} / \mathrm{m}^{2}, \mathrm{DI} / 8 / \mathrm{l} 5 \mathrm{Q} 4 \mathrm{~W}$ \\
\hline Lee $(2013)^{31}$ & 132 & $S B-P+C P$ & 175 mg/m², DI Q3W & 144 & $P M-P+C p$ & $230 \mathrm{mg} / \mathrm{m}^{2}$, DI Q3W \\
\hline \multirow[t]{2}{*}{ Ranade $(2013)^{12}$} & 64 & SB-P & 175 mg/m2, DI Q3W & 66 & PM-P & $220 \mathrm{mg} / \mathrm{m} 2$, DI Q3W \\
\hline & & & & 64 & PM-P & $300 \mathrm{mg} / \mathrm{m} 2$, DI Q3W \\
\hline $\mathrm{Xu}(2013)^{32}$ & 28 & $S B-P+T+O X L$ & 135 mg/m2, DI Q3W & 30 & $N-P+T+O X L$ & $135 \mathrm{mg} / \mathrm{m} 2$, DI Q3W \\
\hline Zeng $(2012)^{33}$ & 71 & $S B-P+C_{P}(C b)$ & 135 mg/m2, DI Q3W & 91 & Lip-P $+C_{p}(C b)$ & $135 \mathrm{mg} / \mathrm{m} 2$, DI Q3W \\
\hline Xie $(2011)^{34}$ & 20 & $S B-P+C b$ & 135 mg/m2, DI Q3W & 35 & Lip-P + Cb & $135 \mathrm{mg} / \mathrm{m} 2$, DI Q3W \\
\hline Gao $(2010)^{35}$ & 32 & SB-P & 175 mg/m2, DI Q3W & 57 & Lip-P & 175 mg/m2, DI Q3D \\
\hline Guan $(2009)^{36}$ & 106 & SB-P & 175 mg/m2, DI Q3W & 104 & N-P & $260 \mathrm{mg} / \mathrm{m} 2$, DI Q3W \\
\hline Langer 2008) $)^{20}$ & 198 & $\mathrm{SB}-\mathrm{P}+\mathrm{Cb}$ & $225 \mathrm{mg} / \mathrm{m} 2$, DI Q3W & 199 & $\mathrm{PPX}+\mathrm{Cb}$ & $210 \mathrm{mg} / \mathrm{m} 2$, DI Q3W \\
\hline Gradishar $(2005)^{37}$ & 222 & SB-P & 175 mg/m2, DI Q3W & 226 & N-P & $260 \mathrm{mg} / \mathrm{m} 2$, DI Q3W \\
\hline Chen $(2003)^{38}$ & 64 & $\begin{array}{l}\mathrm{SB}-\mathrm{P}+(\mathrm{A} / \mathrm{C}) /(\mathrm{CP} / \\
\mathrm{Cb})\end{array}$ & 135 mg/m2, DI Q3W & 64 & $\begin{array}{l}\mathrm{Lip}-\mathrm{P}+(\mathrm{A} / \mathrm{C}) /(\mathrm{CP} / \\
\mathrm{Cb})\end{array}$ & 135 mg/m2, DI Q3W \\
\hline
\end{tabular}

Abbreviations: SB-P, solvent-based paclitaxel; N-P, nanoparticle albumin-bound paclitaxel; Lip-P, liposomal paclitaxel; PM-P, polymeric micelle paclitaxel; PICN, polymericlipidic nanoparticle paclitaxel; PPX, polymer-drug conjugates paclitaxel; NR, no report; AC, doxorubicin/cyclophosphamide; EC, epirubicin/cyclophosphamide; FEC, fluorouracil/epirubicin/cyclophosphamide; Bev, bevacizumab; Cp, Cisplatin; Cb, carboplatin; H, trastuzumab; Per, pertuzumab; T, tegafur; OXL, oxaliplatin; Q2W, every 2 weeks; Q3W, every 3 weeks; Q4W, every 4 weeks.

3452 patients and 334 events (Figure 3A). Sb-P was the most investigated formula (nine studies) followed by Nab-P (three studies), PM-P (three studies), Lip-P (two studies), and PPX (one study). Our analysis showed that the lowest incidence of hypersensitivity reactions of any grade was associated with Lip-P followed by Nab-P, PPX, Sb-P, and PM-P (Figure 4A). The ranking probability for paclitaxel formulation was the highest for Lip-P with 0.614 followed by 0.428 for Nab-P. SUCRA probabilities were as follows: Lip-P, 0.8574; N-P, 0.6544; PPX, 0.6139; Sb-P, 0.3232; and PM-P, 0.05112. No significant inconsistencies were observed between direct and indirect evidence (Figure 5A).

\section{Incidence of Hematological Toxicity}

The incidence of neutropenia of any grade, the number of interventions were six with 13 studies involving 5124 patients and 2951 events (Figure 3B). Sb-P was the most investigated formula (12 studies) followed by Nab-P (six studies), PM-P (four studies), Lip-P (two studies), PPX (one study), and PICN (one study). Our analysis showed that the lowest incidence of neutropenia of any grade was associated with Sb-P followed by Lip-P, PM-P, PPX, Nab$\mathrm{P}$, and PICN (Figure 4B). The ranking probability for paclitaxel formulation was the highest for Lip-P with 0.3009 followed by Sb-P with 0.435 . SUCRA probabilities were as follows: Sb-P, 0.7851; Lip-P, 0.6524; PM-P, 0.6007; PPX, 0.5551; Nab-P, 0.3796; and PICN, 0.02708. No significant inconsistencies were observed between direct and indirect evidence (Figure 5B).

The incidence of leucopenia of any grade, the number of interventions were five with 13 studies involving 4621 patients and 2456 events (Figure 3C). Sb-P was the most investigated formula (12 studies) followed by Nab-P (seven studies), Lip-P (four studies), PM-P (two studies), and PICN (one study). Our analysis showed that the lowest incidence of leucopenia of any grade was associated with Lip-P followed by Sb-P, Nab-P, PM$\mathrm{P}$, and PICN (Figure 4C). The ranking probability for paclitaxel formulation was the highest for Lip-P with 0.9316 followed by 0.8316 for Sb-P. SUCRA probabilities were as follows: Lip-P, 0.9775; Sb-P, 0.7277; Nab-P, 0.2963; PM-P, 0.2849; and PICN, 0.2136. No significant inconsistencies were observed between direct and indirect evidence (Figure 5C). 
Table 3 Characteristics of Cancer Types, Age, Gender and Clinical Stages in All Studies Included in the Network Meta-Analysis

\begin{tabular}{|c|c|c|c|c|}
\hline Author (Year) & Cancer Types & Age(Year) Median & Gender & Clinical Trial \\
\hline Lee $(2018)^{18}$ & Ovarian cancer & $56.4 \pm 10.8 / 55.2 \pm 8.9$ & Female & Phase II \\
\hline Gianni $(2018)^{24}$ & Breast cancer & 50 & Female & Phase III \\
\hline Park $(2017)^{25}$ & Breast cancer & 49 & Female & Phase III \\
\hline Shitara $(2017)^{26}$ & Gastric cancer & $>20$ & Female/male & Phase III \\
\hline Jain $(2016)^{21}$ & Breast cancer & $49 / 50 / 51$ & Female & Phasell/III \\
\hline Untch $(2016)^{27}$ & Breast cancer & $49 / 48$ & Female & Phaselll \\
\hline Rugo $(2015)^{28}$ & Breast cancer & 57 & Female & Phaselll \\
\hline Wang $(2014)^{29}$ & NSCLC & $52.5 \pm 13.0 / 53.8 \pm 10.6$ & Female/male & NR \\
\hline Awada $(2014)^{30}$ & Breast & $53 / 51 / 50.5$ & Female & Phase II \\
\hline Lee $(2013)^{31}$ & NSCLC cancer & $62 / 65$ & Female/male & Phase IIB \\
\hline Ranade $(2013)^{12}$ & Breast cancer & $49 \pm 12 / 49.5 \pm 10 / 50 \pm 10.5$ & Female & Phase II \\
\hline $\mathrm{Xu}(2013)^{32}$ & Gastric cancer & $56 / 54$ & Female/male & NR \\
\hline Zeng $(2012)^{33}$ & Cervical cancer & 47 & Female & NR \\
\hline Xie $(2011)^{34}$ & Cervical cancer & 51.5 & Female & NR \\
\hline Gao $(2010)^{35}$ & NSCLC & $64.5 / 63.5$ & Female/male & NR \\
\hline Guan $(2009)^{36}$ & Breast cancer & 50 & Female & Phase II \\
\hline Langer 2008$)^{20}$ & NSCLC & $61.1 \pm 10.6 / 61.5 \pm 10.1$ & Female/male & Phase III \\
\hline Gradishar $(2005)^{37}$ & Breast cancer & 53 & Female & Phase III \\
\hline Chen $(2003)^{38}$ & Breast/NSCLC & 52.1 & Female/male & NR \\
\hline
\end{tabular}

Abbreviation: NR, no report.

\section{Incidence of Neurotoxicity}

The incidence of peripheral sensory neuropathy of any grade, the number of interventions were six with 15 studies involving 4783 patients and 2969 events (Figure 3D). Sb-P was the most investigated formula (14 studies) followed by Nab-P (six studies), Lip-P (five studies), PM-P (three studies), PPX (one study), and PICN (one study). Our analysis showed that the lowest incidence of peripheral sensory neuropathy of any grade was associated with Lip-P followed by PPX, Sb-P, PM-P, PICN, and Nab-P (Figure 4D). The ranking probability for paclitaxel formulation was the highest for Lip-P with 0.6478 followed by 0.2394 for PPX. SUCRA probabilities were as follows: Lip-P, 0.8925; PPX, 0.5443; Sb-P, 0.5061; PM-P, 0.457; PICN, 0.3222; and
Nab-P, 0.2779. No significant inconsistencies were observed between direct and indirect evidence (Figure 5D).

\section{Incidence of Myalgia}

The incidence of myalgia of any grade, the number of interventions were five with 11 studies involving 3700 patients and 1001 events (Figure 3E). Sb-P was the most investigated formula (11 studies) followed by Nab-P (four studies), PM-P (three studies), Lip-P (three studies), and PPX (one study). Our analysis showed that the lowest incidence of myalgia of any grade was associated with Lip-P followed by PPX, Nab-P, Sb-P, and PM-P (Figure 4E). The ranking probability for paclitaxel formulation was the highest for Lip-P with 0.6565
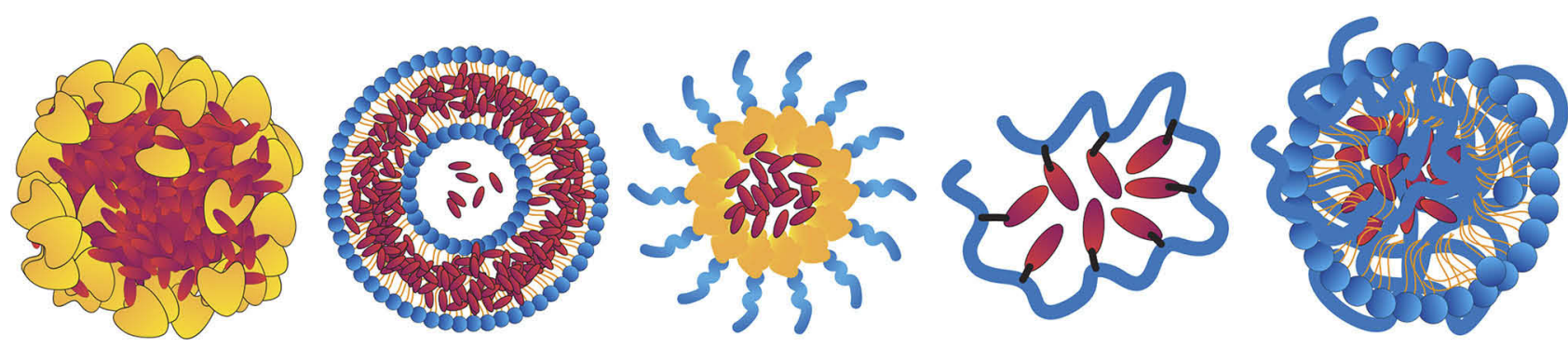

Figure 2 The structure of paclitaxel in various nano-based drug delivery systems. The left to right are Abraxane ${ }^{\circledR}$, Lipusu $^{\circledR}$, Genexol $^{\circledR}, \mathrm{PM} \mathrm{Xyotax}^{\mathrm{TM}}(\mathrm{OPAXIO})$, Taclantis ${ }^{\mathrm{TM}}$, $\left(\right.$ Bevetex $\left.{ }^{\circledR}\right)$. 
A

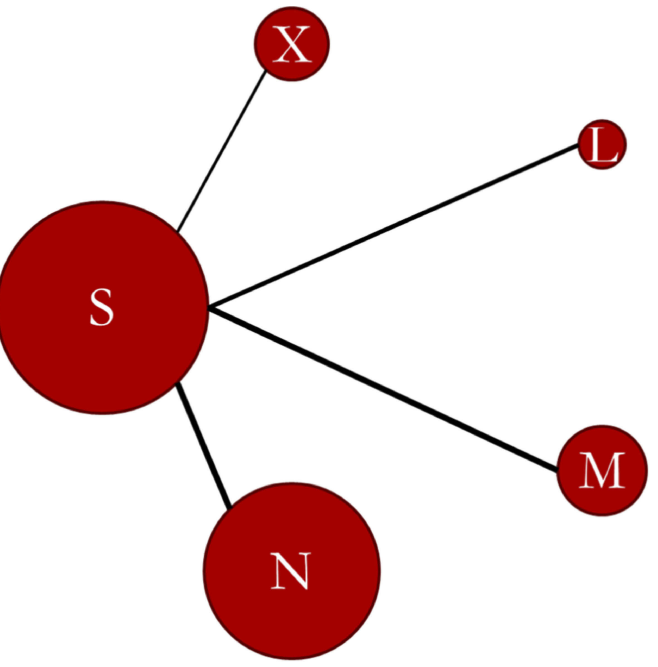

C

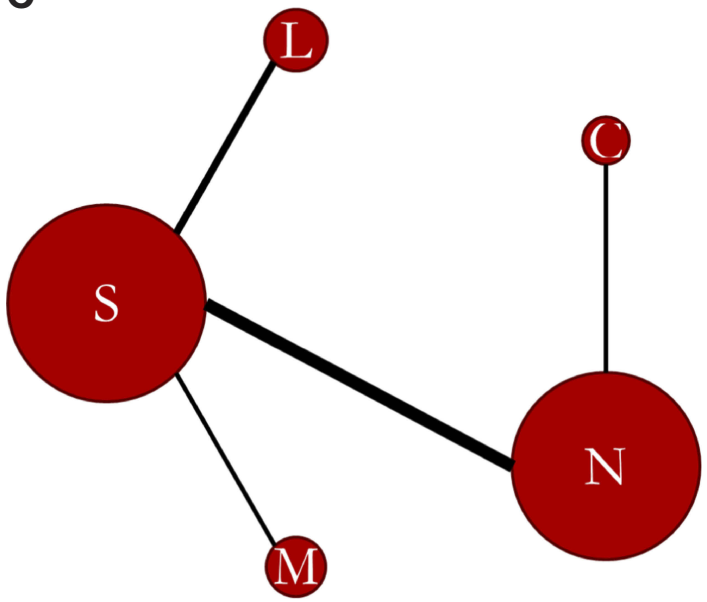

E

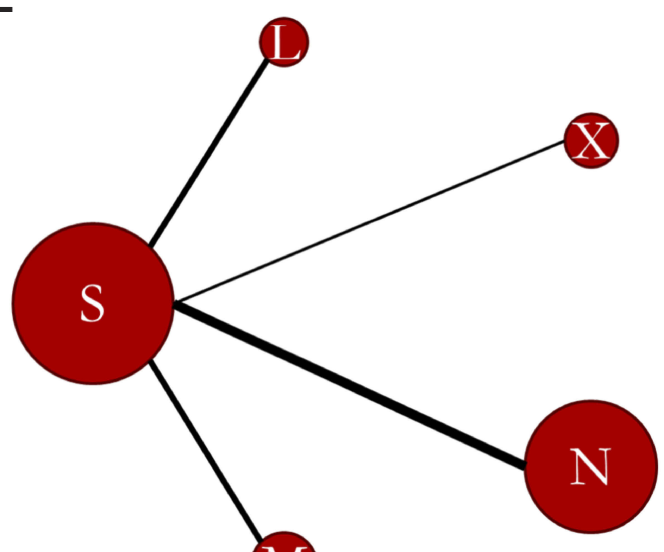

M

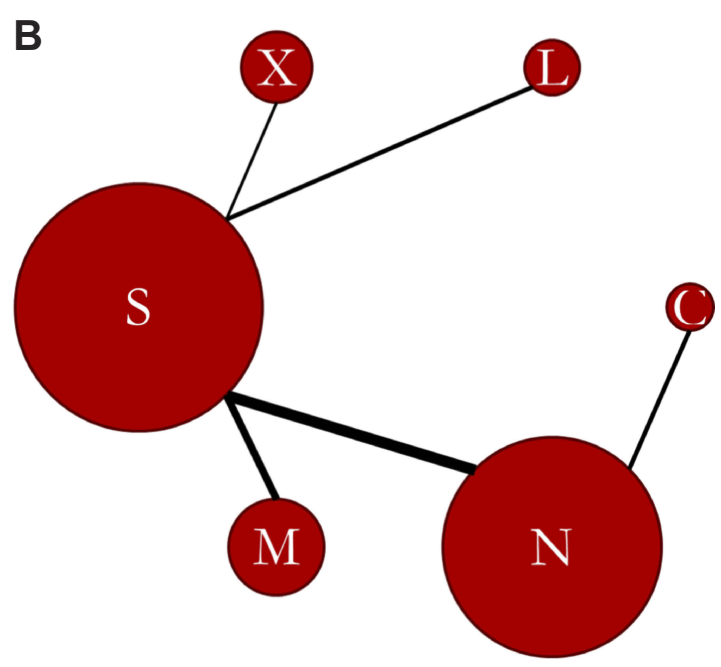

D

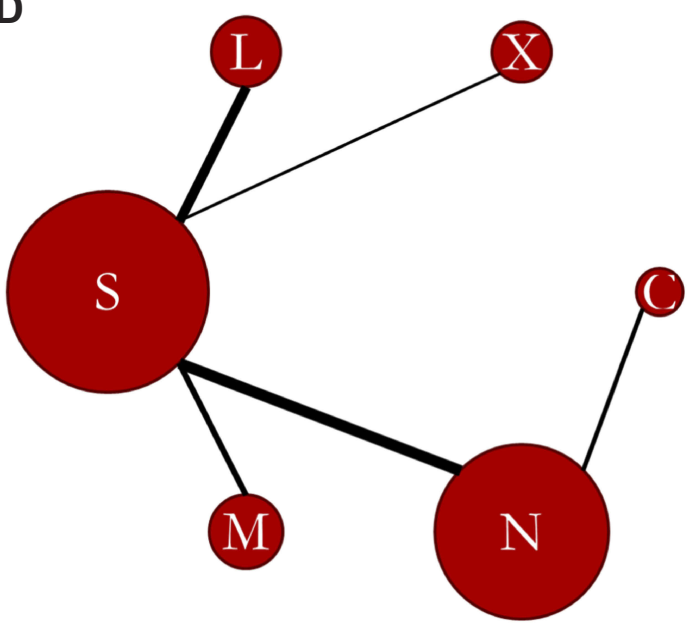

F

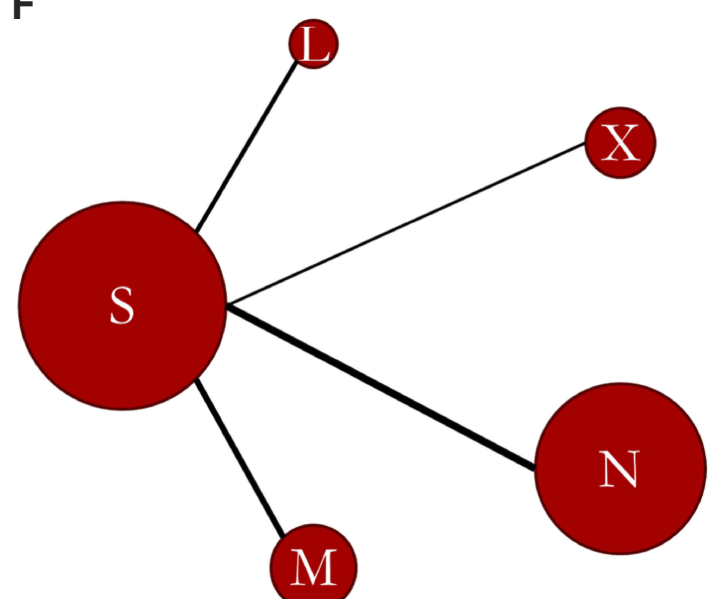

Figure 3 Network diagrams for the incidence rates of each adverse event (A) Hypersensitivity reactions, (B) neutropenia, (C) leucopenia, (D) peripheral sensory neuropathy, (E) myalgia, and (F) arthralgia.

Abbreviations: S, solvent-based paclitaxel; N, nanoparticle albumin- bound paclitaxel; L, liposomal paclitaxel; M, polymeric micelle paclitaxel; C, polymeric-lipidic nanoparticle paclitaxel; $\mathrm{X}$, polymer-drug conjugates paclitaxel. 


\begin{tabular}{|c|c|c|c|c|}
\hline Lip-P & & & & \\
\hline $\begin{array}{c}0.41 \\
(0.03-4.49)\end{array}$ & N-P & & & \\
\hline $\begin{array}{c}0.43 \\
(0.01-11.91)\end{array}$ & $\begin{array}{c}1.04 \\
(0.05-19.38)\end{array}$ & PPX & & \\
\hline $\begin{array}{c}0.19 \\
(0.02-1.30)\end{array}$ & $\begin{array}{c}0.47 \\
(0.11-1.40)\end{array}$ & $\begin{array}{c}0.44 \\
(0.03-5.70)\end{array}$ & SB-P & \\
\hline $\begin{array}{c}0.08 \\
(0.00-0.74)\end{array}$ & $\begin{array}{c}0.20 \\
(0.03-0.96)\end{array}$ & $\begin{array}{c}0.18 \\
(0.01-3.07)\end{array}$ & $\begin{array}{c}0.42 \\
(0.11-1.41)\end{array}$ & PM-P \\
\hline
\end{tabular}
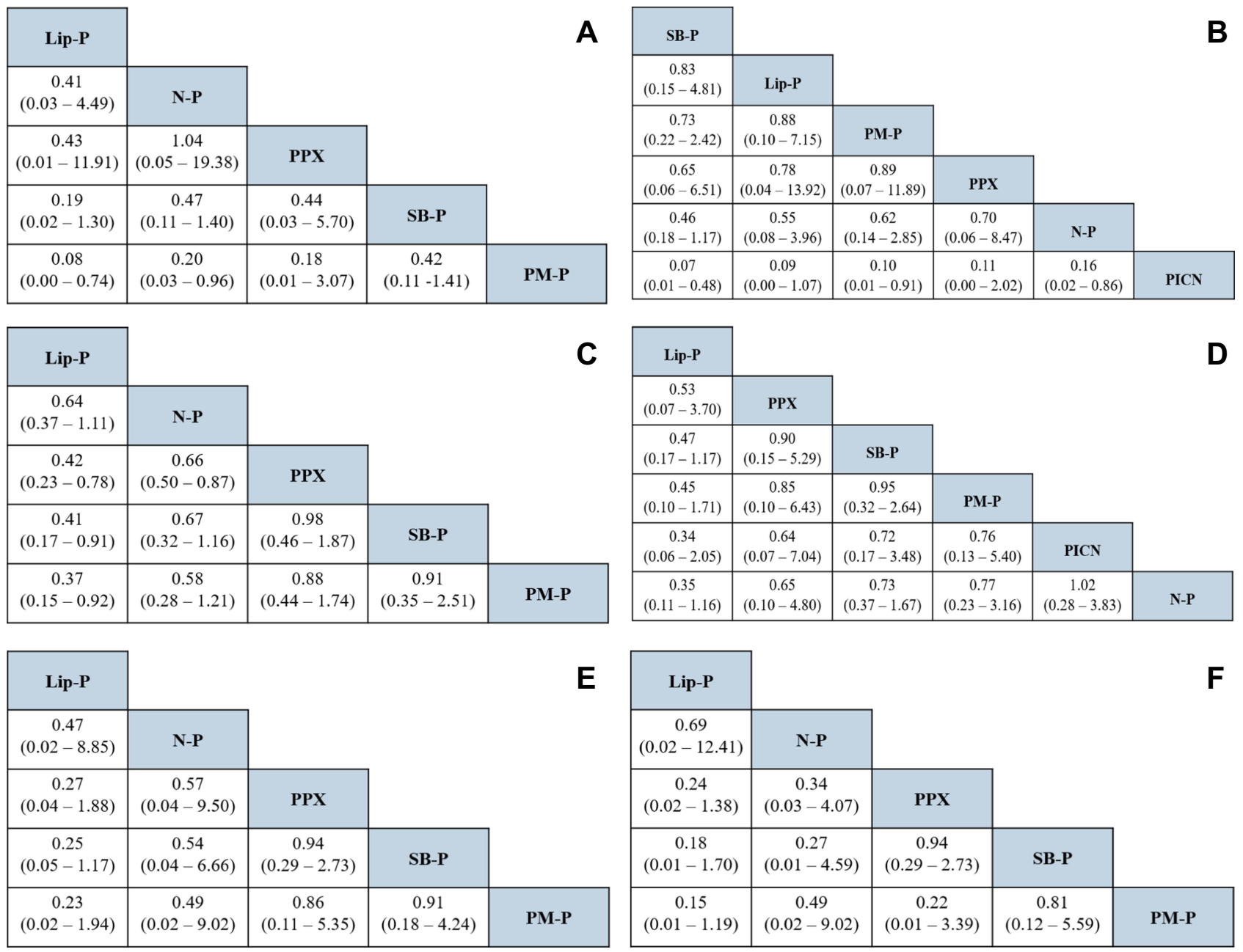

Figure 4 League table showing the odds of the incidence of adverse events associated with different paclitaxel formulations. (A) Hypersensitivity reactions, (B) neutropenia, (C) leucopenia, (D) peripheral sensory neuropathy, (E) myalgia, and (F) arthralgia.

Note: Odds ratio $(O R)<1$ means that the treatment in the top left is superior.

Abbreviations: SB-P, solvent-based paclitaxel; N-P, nanoparticle albumin-bound paclitaxel; Lip-P, Liposomal paclitaxel; PM-P, polymeric micelle paclitaxel; PICN, polymericlipidic nanoparticle paclitaxel; PPX, polymer-drug conjugates paclitaxel.

followed by 0.3239 for PPX. SUCRA probabilities were as follows: Lip-P, 0.8793; PPX, 0.5935; Nab-P, 0.382; Sb-P, 0.3336; and PM-P, 0.3116. No significant inconsistencies were observed between direct and indirect evidence (Figure 5E).

\section{Incidence of Arthralgia}

The incidence of arthralgia of any grade, the number of interventions were five with nine studies involving 3552 patients and 866 events (Figure 3F). Sb-P was the most investigated formula (nine studies) followed by Nab-P (three studies), PM-P (three studies), Lip-P (two studies), and PPX (one study). Our analysis showed that the lowest incidence of arthralgia of any grade was associated with Lip-P followed by PPX, Sb-P, PM-P, and Nab-P (Figure 4F). The ranking probability for paclitaxel formulation was the highest for Lip-P with 0.5843 followed by 0.4048 for PPX. SUCRA probabilities were as follows: Lip-P, 0.8641; PPX, 0.7427; Sb-P, 0.4206; PM-P, 0.2913; and Nab-P, 0.1813. No significant inconsistencies were observed between direct and indirect evidence (Figure 5F).

\section{Discussion}

Paclitaxel plays an important role in cancer therapy as it can be used to treat breast cancer, non-small cell lung cancer (NSCLC), ovarian cancer, and gastric cancer, among others. The CALGB 9342 trial revealed that higher doses of paclitaxel resulted in a slight improvement in time to progression although this was offset by greater toxicity. ${ }^{39}$ It is therefore important to maintain or reduce adverse effects depended by increasing treatment doses. 
A

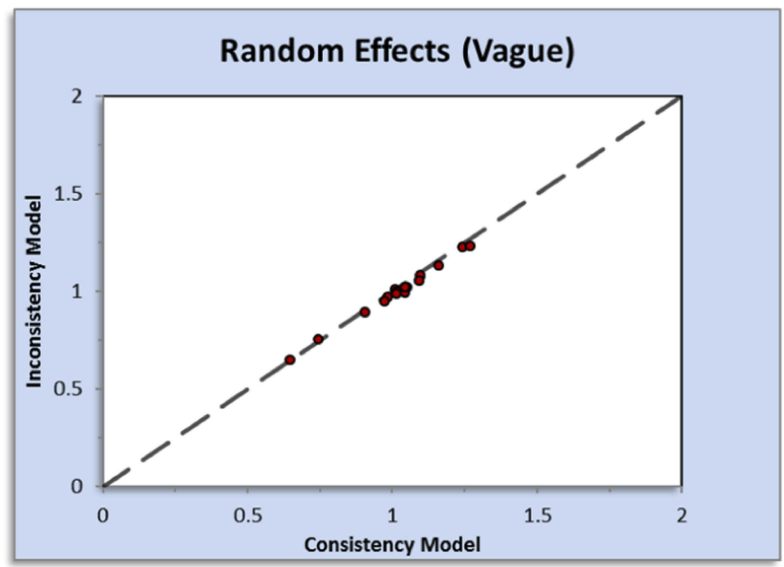

C

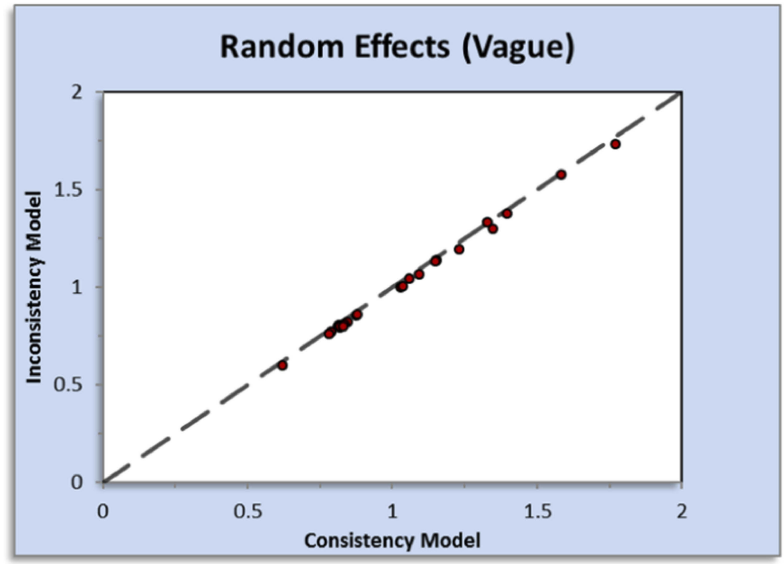

E

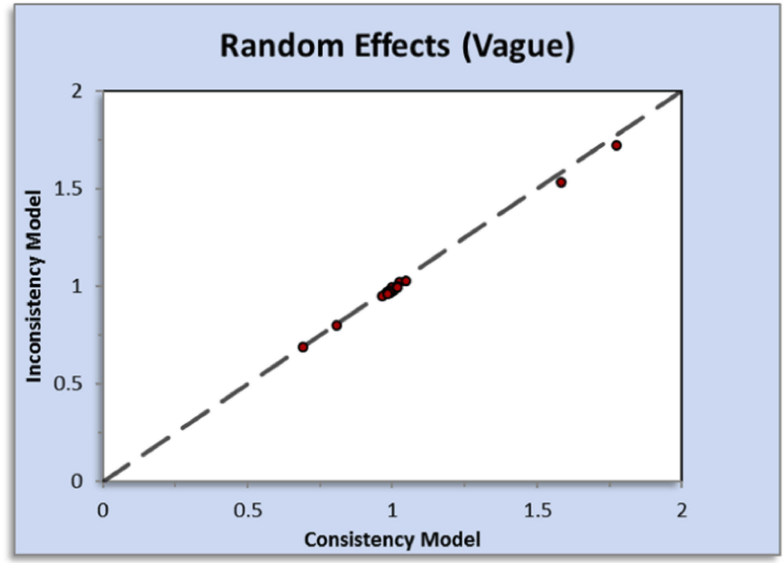

B

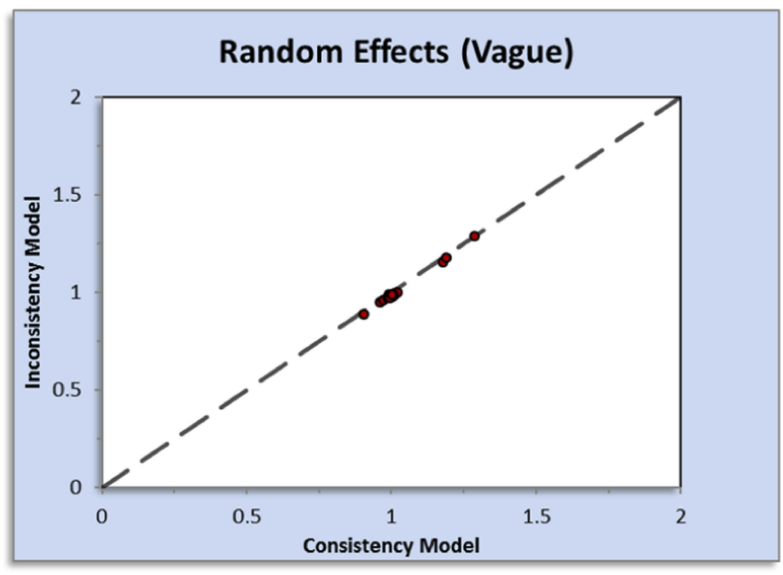

D

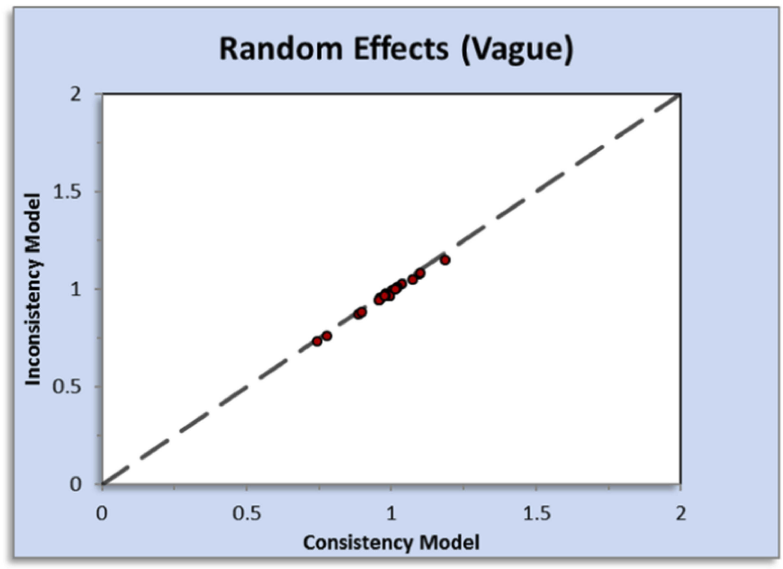

F

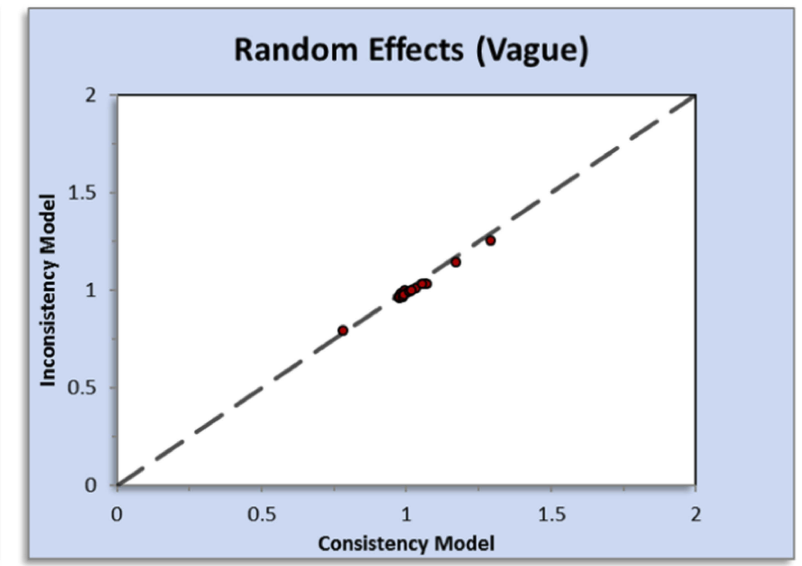

Figure 5 Plot showing the posterior mean deviance of the individual data points in the inconsistency model against their posterior mean deviance in the consistency model. (A) Hypersensitivity reactions, (B) neutropenia, (C) leucopenia, (D) peripheral sensory neuropathy, (E) myalgia, and (F) arthralgi. 
Hypersensitivity reactions were thought to be caused by polyoxyl 35 castor oil, a solvent used to dissolve various water-insoluble drugs, which induced the release of histamine or other vasoactive substances. ${ }^{40}$ To avoid hypersensitivity reactions, prophylactic medication was administered to patients although its efficacy is limited. Bedside preparations are still required for immediate intervention should hypersensitivity reactions occur. ${ }^{41}$

Changing the pharmaceutical formulation to avoid the use of solvent may reduce the occurrence of hypersensitivity reactions. In this NMA, the incidence of hypersensitivity reactions of any grade associated with SB-P was higher than those associated with Lip-P, N-P, and PPX. This incidence was lower than that with PM-P although the difference was not significant.

Therefore, even formulations that do not contain solvent may still cause hypersensitivity reactions in response to other factors. Additionally, different formulations may also have different incidence rates of hypersensitivity reactions resulting from other pharmacokinetic properties. It is noteworthy that even without premedication, the incidence of hypersensitivity reactions to nanoparticle formulations is lower than that associated with SB-P.

Neutropenia and/or leukopenia is the main adverse reaction associated with paclitaxel treatment, and this toxicity is dose-limiting. ${ }^{42-44}$ Leukopenia and neutropenia often result in treatment delays and dose reductions, which have been shown to impact treatment success rate. ${ }^{45}$

Researchers have investigated different infusion times in an attempt to reduce the incidence of neutropenia, ${ }^{39}$ and have used drug-metabolizing enzymes and transporters to predict paclitaxel-associated neutropenia. ${ }^{44,46}$ However, none of these methods have achieved the desired effect. Prophylactic granulocyte-colony stimulating factor (G-CSF or GCSF) is not recommended for routine use. Therefore, effective strategies to reduce the incidence of neutropenia and leukopenia are still required. In this NMA, we compared nanoparticle formulations and showed that SB-P treatment resulted in the lowest incidence of neutropenia of any grade. Conversely, Lip-P resulted in the lowest incidence of leukopenia of any grade although the difference was not significant.

With regard to hematological toxicity, SB-P treatment showed the lowest incidence of neutropenia and leukopenia of any grade. This may be because of the use of higher doses of nanoparticle formulations or alteration of the pharmacokinetics and biodistribution characteristics, which allows a large number of drugs to enter the target site.
Another dose-limiting toxic effect of paclitaxel is neurotoxicity, which is cumulative. ${ }^{47}$ Experimental data have shown that polyoxyl 35 castor oil and paclitaxel both cause peripheral sensory neuropathy. ${ }^{47-49}$ This may present as "glove and stocking" numbness, burning pain, and increased perception with sensory ataxia. Impact on the patient may vary from mild sensory abnormalities to serious impairment of activities and problems with daily life.

Peripheral sensory neuropathy was dependent on the dosage, duration of infusion, and regimen. Severe peripheral sensory neuropathy occurs more frequently with high doses per cycle $\left(>250 \mathrm{mg} / \mathrm{m}^{2}\right)$ or at a high cumulative dosage $\left(>1400 \mathrm{mg} / \mathrm{m}^{2}\right) .{ }^{47}$ Additionally, extending the duration of infusion to $24 \mathrm{~h}$ instead of $3 \mathrm{~h}$ increased the incidence of peripheral sensory neuropathy. ${ }^{46}$

Several medications have been investigated as neuroprotective agents for the prevention of peripheral sensory neuropathy, including amifostine, glutamate, nerve growth factor, and vitamin E, among others, although the protection conferred was limited. ${ }^{47,50}$ There are currently no methods to prevent or cure peripheral sensory neuropathy other than symptomatic treatment, which includes the use of the tricyclic antidepressant amitriptyline to relieve painful neuropathy. ${ }^{47}$ In this NMA, the incidence of peripheral sensory neuropathy of any grade associated with SB-P treatment was similar to that associated with other nanoparticle formulations.

Myalgia and arthralgia are prominent toxicities associated with paclitaxel treatment. ${ }^{44}$ The signs and symptoms are self-limiting and are dependent on the dose of paclitaxel administered. ${ }^{51,52}$ Nonsteroidal anti-inflammatory agents (NSAID) and narcotic analgesia are helpful in reducing symptom severity. ${ }^{1}$ Additionally, low-dose oral prednisone regimen may result in significant improvement in most patients experiencing paclitaxel-associated myalgia or arthralgia. ${ }^{52}$

A study in Japan assessed the efficacy of ShakuyakuKanzo-to for prophylaxis against paclitaxel-associated myalgia and arthralgia, and showed that the mean duration of myalgia and arthralgia symptoms in the ShakuyakuKanzo-to group was $2.78 \pm 2.09$ days versus $5.08 \pm 2.89$ days in the control group. The mean duration and grades of myalgia and arthralgia were significantly lower in the Shakuyaku-Kanzo-to group. ${ }^{53}$ In this study, the incidence rates of myalgia and arthralgia of any grade associated with SB-P were similar to those associated with other nanoparticle formulations. 
Altering paclitaxel formulations may modulate adverse reactions. This study highlights the fact that the potential clinical benefits of nanoparticle paclitaxel formulations should be weighed against the increased risk of ADRs.

This study has several limitations. First, the information regarding ADRs reported in the included studies may be incomplete and limited. Second, different doses and treatment regimens were used in the collected studies. Third, the study design of several included studies comprised chemotherapy in combination with other agents. These limitations may have contributed to non-significant results. More studies are needed to confirm the advantages and disadvantages of various paclitaxel formulations.

\section{Conclusion}

Nano-based paclitaxel delivery systems show lower incidence rates of hypersensitivity reactions than solvent-based paclitaxel treatment. The incidence rates of neutropenia and leucopenia were higher with nano-based paclitaxel delivery than with solvent-based paclitaxel treatment. The incidence rates of peripheral sensory neuropathy, myalgia, and arthralgia were not significantly different between different formulations. These results indicate the need to consider the potential clinical benefits of nanoparticle paclitaxel formulation against the increased risk of ADRs. Moreover, reduce the dose requirement in the therapeutic regiments is more important issue.

\section{Disclosure}

The authors report no conflicts of interest in this work.

\section{References}

1. Markman M. Managing taxane toxicities. Support Care Cancer. 2003;11(3):144-147. doi:10.1007/s00520-002-0405-9

2. Rowinsky EK, Donehower RC. Paclitaxel (taxol). $N$ Engl J Med. 1995;332(15):1004-1014. doi:10.1056/NEJM199504133321507

3. Allen TM, Cullis PR. Drug delivery systems: entering the mainstream. Science. 2004;303(5665):1818-1822. doi:10.1126/science.1095833

4. De Jong WH, Borm PJ. Drug delivery and nanoparticles: applications and hazards. Int J Nanomedicine. 2008;3(2):133-149. doi:10.2147/IJN

5. Mastropaolo D, Camerman A, Luo Y, Brayer GD, Camerman N. Crystal and molecular structure of paclitaxel (taxol). Proc Natl Acad Sci U S A. 1995;92(15):6920-6924. doi:10.1073/pnas.92.15.6920

6. Singla AK, Garg A, Aggarwal D. Paclitaxel and its formulations. Int J Pharm. 2002;235(1-2):179-192. doi:10.1016/S0378-5173(01) 00986-3

7. Merisko-liversidge E, Sarpotdar P, Bruno J, et al. Formulation and antitumor activity evaluation of nanocrystalline suspensions of poorly soluble anticancer drugs. Pharm Res. 1996;13(2):272-278. doi:10. 1023/A:1016051316815
8. Constantinides PP, Lambert KJ, Tustian AK, et al. Formulation development and antitumor activity of a filter-sterilizable emulsion of paclitaxel. Pharm Res. 2000;17(2):175-182. doi:10.1023/A:1007 565230130

9. emc [Website on the Internet]. Available from: https://www.medi cines.org.uk/emc/product/6076/smpc\#PHARMACEUTICAL_ PARTS. Accessed February 25, 2020.

10. Surapaneni MS, Das SK, Das NG. Designing paclitaxel drug delivery systems aimed at improved patient outcomes: current status and challenges. ISRN Pharmacol. 2012;2012:623139. doi:10.5402/2012/ 623139

11. Patra JK, Das G, Fraceto LF, et al. Nano based drug delivery systems: recent developments and future prospects. J Nanobiotechnology. 2018;16(1):71. doi:10.1186/s12951-018-0392-8

12. Ranade AA, Bapsy PP, Nag S, et al. A multicenter phase II randomized study of cremophor-free polymeric nanoparticle formulation of paclitaxel in women with locally advanced and/or metastatic breast cancer after failure of anthracycline. Asia Pac J Clin Oncol. 2013;9 (2):176-181. doi:10.1111/ajco.12035

13. Miele E, Spinelli GP, Miele E, Tomao F, Tomao S. Albumin-bound formulation of paclitaxel (Abraxane ABI-007) in the treatment of breast cancer. Int J Nanomedicine. 2009;4:99-105. doi:10.2147/ijn.s3061

14. Ibrahim NK, Desai N, Legha S, et al. Phase I and pharmacokinetic study of ABI-007, a cremophor-free, protein-stabilized, nanoparticle formulation of paclitaxel. Clin Cancer Res. 2002;8(5):1038-1044.

15. Koudelka S, Turanek J. Liposomal paclitaxel formulations. J Control Release. 2012;163(3):322-334. doi:10.1016/j.jconrel.2012.09.006

16. Croy SR, Kwon GS. Polymeric micelles for drug delivery. Curr Pharm Des. 2006;12(36):4669-4684. doi:10.2174/138161206779026245

17. Kim SC, Kim DW, Shim YH, et al. In vivo evaluation of polymeric micellar paclitaxel formulation: toxicity and efficacy. $J$ Control Release. 2001;72(1-3):191-202. doi:10.1016/S0168-3659(01)00275-9

18. Lee SW, Kim YM, Cho $\mathrm{CH}$, et al. An open-label, randomized, parallel, phase II trial to evaluate the efficacy and safety of a cremophor-free polymeric micelle formulation of paclitaxel as first-line treatment for ovarian cancer: a Korean Gynecologic Oncology Group study (KGOG-3021). Cancer Res Treat. 2018;50 (1):195-203. doi:10.4143/crt.2016.376

19. Li C, Wallace S. Polymer-drug conjugates: recent development in clinical oncology. Adv Drug Deliv Rev. 2008;60(8):886-898. doi:10. 1016/j.addr.2007.11.009

20. Langer CJ, O’byrne KJ, Socinski MA, et al. Phase III trial comparing paclitaxel poliglumex (CT-2103, PPX) in combination with carboplatin versus standard paclitaxel and carboplatin in the treatment of PS 2 patients with chemotherapy-naive advanced non-small cell lung cancer. J Thorac Oncol. 2008;3(6):623-630. doi:10.1097/JTO.0b0 $13 \mathrm{e} 3181753 \mathrm{~b} 4 \mathrm{~b}$

21. Jain MM, Gupte SU, Patil SG, et al. Paclitaxel injection concentrate for nanodispersion versus nab-paclitaxel in women with metastatic breast cancer: a multicenter, randomized, comparative phase II/III study. Breast Cancer Res Treat. 2016;156(1):125-134. doi:10.1007/ s10549-016-3736-9

22. Critical Appraisal Skills Programme. CASP randomised controlled trial checklist. [online]; 2018. Available from: https://casp-uk.net/wpcontent/uploads/2018/03/CASP-Randomised-Controlled-TrialChecklist-Download.pdf. Accessed March 29, 2018.

23. Brown S, Hutton B, Clifford T, et al. A Microsoft-Excel-based tool for running and critically appraising network meta-analyses-an overview and application of NetMetaXL. Syst Rev. 2014;3:110. doi:10. 1186/2046-4053-3-110

24. Gianni L, Mansutti M, Anton A, et al. Comparing neoadjuvant nab-paclitaxel vs paclitaxel both followed by anthracycline regimens in women with ERBB2/HER2-negative breast cancer-the Evaluating Treatment With Neoadjuvant Abraxane (ETNA) Trial: a randomized phase 3 clinical trial. JAMA Oncol. 2018;4(3):302-308. doi:10.1001/ jamaoncol.2017.4612 
25. Park IH, Sohn JH, Kim SB, et al. An open-label, randomized, parallel, phase III trial evaluating the efficacy and safety of polymeric micelle-formulated paclitaxel compared to conventional cremophor EL-based paclitaxel for recurrent or metastatic HER2-negative breast cancer. Cancer Res Treat. 2017;49(3):569-577. doi:10.4143/crt.20 16.289

26. Shitara K, Takashima A, Fujitani K, et al. Nab-paclitaxel versus solvent-based paclitaxel in patients with previously treated advanced gastric cancer (ABSOLUTE): an open-label, randomised, non-inferiority, phase 3 trial. Lancet Gastroenterol Hepatol. 2017;2 (4):277-287. doi:10.1016/S2468-1253(16)30219-9

27. Untch M, Jackisch C, Schneeweiss A, et al. Nab-paclitaxel versus solvent-based paclitaxel in neoadjuvant chemotherapy for early breast cancer (GeparSepto-GBG 69): a randomised, phase 3 trial. Lancet Oncol. 2016;17(3):345-356. doi:10.1016/S1470-2045(15)00542-2

28. Rugo HS, Barry WT, Moreno-aspitia A, et al. Randomized phase III trial of paclitaxel once per week compared with nanoparticle albumin-bound nab-paclitaxel once per week or ixabepilone with bevacizumab as first-line chemotherapy for locally recurrent or metastatic breast cancer: CALGB 40502/NCCTG N063H (alliance). J Clin Oncol. 2015;33(21):2361-2369. doi:10.1200/JCO.2014.59.5298

29. Wang HY, Zhang XR. Comparison of efficacy and safety between liposome-paclitaxel injection plus carboplatin and paclitaxel plus carboplatin as first line treatment in advanced non-small cell lung cancer. Zhongguo Yi Xue Ke Xue Yuan Хие Bao. 2014;36(3):305-308. doi:10.3881/j.issn.1000-503X.2014.03.014

30. Awada A, Bondarenko IN, Bonneterre J, et al. A randomized controlled phase II trial of a novel composition of paclitaxel embedded into neutral and cationic lipids targeting tumor endothelial cells in advanced triple-negative breast cancer (TNBC). Ann Oncol. 2014;25 (4):824-831. doi:10.1093/annonc/mdu025

31. Lee SY, Park HS, Lee KY, et al. Paclitaxel-loaded polymeric micelle $(230 \mathrm{mg} / \mathrm{m} 2)$ and cisplatin $(60 \mathrm{mg} / \mathrm{m} 2)$ vs. paclitaxel $(175 \mathrm{mg} / \mathrm{m} 2)$ and cisplatin $(60 \mathrm{mg} / \mathrm{m} 2)$ in advanced Non-small-cell lung cancer: a multicenter randomized phase IIB trial. Clin Lung Cancer. 2013;14 (3):275-282. doi:10.1016/j.cllc.2012.11.005

32. Xu X, Wang L, Xu HQ, Huang XE, Qian YD, Xiang J. Clinical comparison between paclitaxel liposome (Lipusu ${ }^{\circledR}$ ) and paclitaxel for treatment of patients with metastatic gastric cancer. Asian Pac J Cancer Prev. 2013;14(4):2591-2594. doi:10.7314/APJCP.2013.14.4.2591

33. Zeng S, Ling L, Zhong M, et al. A randomized controlled trial of two chemotherapy regimens - paclitaxel liposome combined with platinum and paclitaxel combined with platinum in concurrent chemoradiotherapy for cervical carcinoma. Chin Ger J Clin Oncol. 2012;33 (7):517-519.

34. Xie S-Z, Liu H, Chen Z-L, Song C-W, Wang J. Clinical and pathological study of neoadjuvant chemotherapy with paclitaxel liposome in bulky cervical cancer. Chin J Cancer Prev. 2011;18 (6):460-462.

35. Gao J, Guan S, Deng W, Qiu G, Rao Z, Zhang B. Clinical study of comparing LP and TP regimens in the treatment of advanced non-small cell lung cancer. Chin Ger J Clin Oncol. 2010;9(4):3. doi:10.1007/s10330-010-0031-9

36. Guan -Z-Z, Li QL, Feng F, et al. Superior efficacy of a Cremophor-free albumin-bound paclitaxel compared with solvent-based paclitaxel in Chinese patients with metastatic breast cancer. Asia-Pac J Clin Oncol. 2009;5(3):10. doi:10.1111/j.17437563.2009.01235.x

37. Gradishar WJ, Tjulandin S, Davidson N, et al. Phase III trial of nanoparticle albumin-bound paclitaxel compared with polyethylated castor oil-based paclitaxel in women with breast cancer. J Clin Oncol. 2005;23(31):7794-7803. doi:10.1200/JCO.2005.04.937
38. Chen Q, Zhang QZ, Liu J, et al. [Multi-center prospective randomized trial on paclitaxel liposome and traditional taxol in the treatment of breast cancer and non-small-cell lung cancer]. Zhonghua Zhong Liu Za Zhi. 2003;25(2):190-192. Chinese.

39. Winer EP, Berry DA, Woolf S, et al. Failure of higher-dose paclitaxel to improve outcome in patients with metastatic breast cancer: cancer and leukemia group B trial 9342. J Clin Oncol. 2004;22 (11):2061-2068. doi:10.1200/JCO.2004.08.048

40. Rao S, Krauss NE, Heerding JM, et al. 3'-(p-azidobenzamido)taxol photolabels the N-terminal 31 amino acids of beta-tubulin. $J$ Biol Chem. 1994;269(5):3132-3134.

41. Weiss RB, Donehower RC, Wiernik PH, et al. Hypersensitivity reactions from taxol. J Clin Oncol. 1990;8(7):1263-1268. doi:10.1200/ JCO.1990.8.7.1263

42. Rowinsky EK, Eisenhauer EA, Chaudhry V, Arbuck SG, Donehower RC. Clinical toxicities encountered with paclitaxel (taxol). Semin Oncol. 1993;20(4 Suppl 3):1-15.

43. Markman M. Taxol: an important new drug in the management of epithelial ovarian cancer. Yale J Biol Med. 1991;64(6):583-590.

44. Nieuweboer AJ, Smid M, de Graan AJ, et al. Predicting paclitaxel-induced neutropenia using the DMET platform. Pharmacogenomics. 2015;16(11):1231-1241. doi:10.2217/ pgs. 15.68

45. Aapro MS, Cameron DA, Pettengell R, et al. EORTC guidelines for the use of granulocyte-colony stimulating factor to reduce the incidence of chemotherapy-induced febrile neutropenia in adult patients with lymphomas and solid tumours. Eur $J$ Cancer. 2006;42(15):2433-2453. doi:10.1016/j.ejca.2006.05.002

46. Eisenhauer EA, Ten Bokkel Huinink WW, Swenerton KD, et al. European-Canadian randomized trial of paclitaxel in relapsed ovarian cancer: high-dose versus low-dose and long versus short infusion. J Clin Oncol. 1994;12(12):2654-2666. doi:10.1200/JCO.1994.12.12. 2654

47. Scripture CD, Figg WD, Sparreboom A. Peripheral neuropathy induced by paclitaxel: recent insights and future perspectives. Curr Neuropharmacol. 2006;4(2):165-172. doi:10.2174/15701590677635 9568

48. Gelderblom H, Verweij J, Nooter K, Sparreboom A. Cremophor EL. Eur J Cancer. 2001;37(43):1590. doi:10.1016/S0959-8049(01) 00171-X

49. Mielke S, Sparreboom A, Steinberg SM et al. Association of paclitaxel pharmacokinetics with the development of peripheral neuropathy in patients with advanced cancer. Clin Cancer Res. 2005;11(13):4843-4850. doi:10.1158/1078-0432.CCR-050298

50. Gelmon K, Eisenhauer E, Bryce C, et al. Randomized phase II study of high-dose paclitaxel with or without amifostine in patients with metastatic breast cancer. J Clin Oncol. 1999;17(10):3038-3047. doi:10.1200/JCO.1999.17.10.3038

51. Jacobson SD, Loprinzi CL, Sloan JA, et al. Glutamine does not prevent paclitaxel-associated myalgias and arthralgias. J Support Oncol. 2003;1(4):274-278.

52. Markman M, Kennedy A, Webster K, Kulp B, Peterson G, Belinson J. Use of low-dose oral prednisone to prevent paclitaxel-induced arthralgias and myalgias. Gynecol Oncol. 1999;72(1):100-101. doi:10.1006/gyno.1998.5226

53. Yoshida $T$, Sawa $T$, Ishiguro $T$, Horiba $A$, Minatoguchi $S$, Fujiwara H. The efficacy of prophylactic Shakuyaku-Kanzo-to for myalgia and arthralgia following carboplatin and paclitaxel combination chemotherapy for non-small cell lung cancer. Support Care Cancer. 2009;17(3):315-320. doi:10.1007/s00520-008-0508-z 


\section{Publish your work in this journal}

The International Journal of Nanomedicine is an international, peerreviewed journal focusing on the application of nanotechnology in diagnostics, therapeutics, and drug delivery systems throughout the biomedical field. This journal is indexed on PubMed Central, MedLine, CAS, SciSearch ${ }^{\mathbb{R}}$, Current Contents ${ }^{\mathbb{B}} /$ Clinical Medicine,
Journal Citation Reports/Science Edition, EMBase, Scopus and the Elsevier Bibliographic databases. The manuscript management system is completely online and includes a very quick and fair peer-review system, which is all easy to use. Visit http://www.dovepress.com/ testimonials.php to read real quotes from published authors.

Submit your manuscript here: https://www.dovepress.com/international-journal-of-nanomedicine-journal 